\title{
lodine status five years after the adjustment of universal salt iodization: a cross-sectional study in Fujian Province, China
}

\author{
Yixuan Lin $^{1,2+}$, Diqun Chen ${ }^{1 \dagger}$, Jiani Wu ${ }^{1}$ and Zhihui Chen ${ }^{1,3^{*}}$
}

\begin{abstract}
Background: Universal salt iodization program was introduced to China to eliminate iodine deficiency disorders in 1995. In 2012, Fujian Province decreased the concentration of iodized table salt according to the national unified requirement. This study aimed to assess the effect on iodine status after the adjustment, providing evidence for further adjustment in Fujian Province.

Methods: Sampling units were selected by multistage cluster sampling method. In each sampling unit, table salt was collected from 30 households. A total of 2,471 people in 2009 and 4,806 people in 2017 provided urine samples and were included in this cross-sectional analysis. Median iodized salt concentration and median urine iodine concentration were present by median and interquartile range.

Results: Median iodized salt decreased from $29.8 \mathrm{mg} / \mathrm{kg}$ in 2009 to $23.9 \mathrm{mg} / \mathrm{kg}$ in 2017. The median urinary iodine concentrations for school-age children in 2017 in coastal urban area, non-coastal urban area, coastal rural area and non-coastal rural area were $163.6 \mu \mathrm{g} / \mathrm{L}$ (interquartile range $=100.1-252.0 \mu \mathrm{g} / \mathrm{L}$ ), $198.9 \mu \mathrm{g} / \mathrm{L}$ (interquartile range $=128.0$ $294.0 \mu \mathrm{g} / \mathrm{L}$ ), $181.8 \mu \mathrm{g} / \mathrm{L}$ (interquartile range $=114.1-257.0 \mu \mathrm{g} / \mathrm{L}$ ) and $218.2 \mu \mathrm{g} / \mathrm{L}$ (interquartile range $=148.1-306.5 \mu \mathrm{g} / \mathrm{L}$ ), respectively. The median urinary iodine concentrations for adults in 2017 in these areas were $151.1 \mu \mathrm{g} / \mathrm{L}$ (interquartile range $=98.3-231.7 \mu \mathrm{g} / \mathrm{L}$ ), $168.7 \mu \mathrm{g} / \mathrm{L}$ (interquartile range $=109.6-242.0 \mu \mathrm{g} / \mathrm{L}$ ), $167.7 \mu \mathrm{g} / \mathrm{L}$ (interquartile range $=105.7$ $245.7 \mu \mathrm{g} / \mathrm{L}$ ) and $182.7 \mu \mathrm{g} / \mathrm{L}$ (interquartile range $=117.1-258.9 \mu \mathrm{g} / \mathrm{L}$ ). The median urinary iodine concentrations for pregnant women in 2017 in these areas were $157.7 \mu \mathrm{g} / \mathrm{L}$ (interquartile range $=106.9-223.8 \mu \mathrm{g} / \mathrm{L}$ ), $141.5 \mu \mathrm{g} / \mathrm{L}$ (interquartile range $=97.7-207.6 \mu \mathrm{g} / \mathrm{L}$ ), $127.3 \mu \mathrm{g} / \mathrm{L}$ (interquartile range $=90.0-184.5 \mu \mathrm{g} / \mathrm{L}$ ) and $144.8 \mu \mathrm{g} / \mathrm{L}$ (interquartile range $=99.9-$ $184.5 \mu \mathrm{g} / \mathrm{L})$. The median urinary iodine concentrations for lactating women in $2017 \mathrm{in}$ these areas were 122.7 $\mathrm{\mu g} / \mathrm{L}$ (interquartile range $=84.1-172.0 \mu \mathrm{g} / \mathrm{L}$ ), $123.7 \mu \mathrm{g} / \mathrm{L}$ (interquartile range $=70.7-184.7 \mu \mathrm{g} / \mathrm{L}$ ), $105.8 \mu \mathrm{g} / \mathrm{L}$ (interquartile range $=$ $67.1-152.3 \mu \mathrm{g} / \mathrm{L}$ ) and $110.2 \mu \mathrm{g} / \mathrm{L}$ (interquartile range $=74.1-170.3 \mu \mathrm{g} / \mathrm{L}$ ).

(Continued on next page)
\end{abstract}

\footnotetext{
* Correspondence: 18906913056@163.com

${ }^{\dagger}$ Yixuan Lin and Diqun Chen contributed equally to this work.

${ }^{1}$ Fujian Center for Disease Control and Prevention, Department of Endemic

Diseases, Fujian, No. 76 Jintai Road, Fujian 350001 Fuzhou, People's Republic

of China

${ }^{3}$ School of Public Health, Fujian Medical University, University of New Area, No.1 Xueyuan Road, Fujian 350108 Fuzhou, People's Republic of China

Full list of author information is available at the end of the article
}

(c) The Author(s). 2021 Open Access This article is licensed under a Creative Commons Attribution 4.0 International License, which permits use, sharing, adaptation, distribution and reproduction in any medium or format, as long as you give appropriate credit to the original author(s) and the source, provide a link to the Creative Commons licence, and indicate if changes were made. The images or other third party material in this article are included in the article's Creative Commons licence, unless indicated otherwise in a credit line to the material. If material is not included in the article's Creative Commons licence and your intended use is not permitted by statutory regulation or exceeds the permitted use, you will need to obtain permission directly from the copyright holder. To view a copy of this licence, visit http://creativecommons.org/licenses/by/4.0/ The Creative Commons Public Domain Dedication waiver (http://creativecommons.org/publicdomain/zero/1.0/) applies to the data made available in this article, unless otherwise stated in a credit line to the data. 


\begin{abstract}
(Continued from previous page)
Conclusions: The overall urinary iodine concentrations among school-age children, adults and lactating women dramatically decreased after implementing the new standard. Almost all of them were iodine adequate, suggesting we reached the expected aim of iodized salt adjustment. However, pregnant women were iodine insufficient after adjustment. Therefore, we should continue the surveillance of iodine status of populations and focus on the additional iodine supplement strategies for pregnant women.
\end{abstract}

Keywords: Adjustment, lodized salt, Urine iodine concentration, lodine status

\section{Introduction}

Iodine is an essential element for thyroid hormones production, playing an important role in our early life, influencing human's neurodevelopment, growth and cellular metabolism $[1,2]$. Lack of iodine can cause iodine deficiency disorders (IDD), including abortion, stillbirth among fetuses, endemic cretinism among neonate, delayed physical development among children and adolescents and endemic goiter among all age groups. Excess iodine can also cause side effects, such as hypothyroidism and autoimmune thyroid $[3,4]$.

Iodine deficiency is a public health issue in the world [5], and it was also a public health issue in China before 1995 [6], becoming an obstacle on the way of Chinese economic development and national quality improvement. Some developed countries choose bread and milk as carriers while China chooses salt as the most costeffective and simplest carrier [7-10]. In 1995 China launched the Universal salt iodization program aiming for improving health for citizens particularly among children and women. After the implementation of this program, people's iodine intake mainly comes from iodized salt. By 2000, the Chinese Ministry of Health announced that China had reached the goal of eliminating IDD. However, the national iodine surveillance pointed out that the median urinary iodine concentration (mUIC) in some provinces was above $300 \mu \mathrm{g} / \mathrm{L}$ if the iodized salt concentration was between 40 and $60 \mathrm{mg} / \mathrm{kg}$. Then the government adjusted the standard of the concentration from 40 to $60 \mathrm{mg} / \mathrm{kg}$ to $20-50 \mathrm{mg} / \mathrm{kg}$ [6]. However, a couple of provinces were still maintained a relatively high mUIC because of the high-salt diet, and there were some possibilities for a small its reduction [11]. Given that salt consumption differs in different geographical areas, each province has been authorized to set its concentration criterion based on their geographical factors and population iodine status since March 2012. Fujian set its criterion between 18 and $33 \mathrm{mg} / \mathrm{kg}$.

This study aimed to assess the iodine status in Fujian Province 5 years after the adjustment of universal salt iodization, thereby investigating the appropriateness of iodine status between populations, the differences of iodine status before and after the adjustment, evaluating the rationality of the adjustment and trying to give some suggestions for the iodized salt concentration adjustment.

\section{Methods}

\section{Study design and participants}

This cross-sectional study employed the multistage cluster sampling method in 2009 and 2017. There are 9 administrative regions in Fujian Province. An urban area and a rural area were randomly selected from each administrative region. One district was randomly selected from an urban or rural area; one town was randomly selected from the selected district; one village was randomly selected from the selected town. The 18 sampling units were classified as coastal or non-coastal units based on their geographical location. There were 4 units classified into coastal urban area, 5 units classified into non-coastal urban area, 6 units classified into coastal rural area and 3 units classified into non-coastal rural area.

The participants from the villages were recruited, and the inclusion criteria were who were: (1) healthy; (2) local residents. The exclusion criteria were who: (1) lived in this area less than 5 years; (2) were receiving or treated with amiodarone; (3) with abnormal renal function; (4) used coronary angiography or endoscopic retrograde cholangiopancreatography within 6 months. In 2009 and 2017, thirty households were randomly selected from each village, a salt sample with at least $30 \mathrm{~g}$ was collected from a household, and the samples were protected from the light until the detection. In 2009, 20 adults aged 18 to 45 were randomly selected from each sampling unit, half male and half female. 30 pregnant women, 30 lactating women and 50 school-age children (half male and half female) from one elementary school aged 8 to 10 were randomly selected from the sampling unit as well. In 2017, 60 adults aged 20 to 50 were selected from each sampling unit, half male and half female. 50 pregnant women, 50 lactating women and 100 school-age children half male and half female from one elementary school aged 8 to 10 were randomly selected from the sampling unit as well. $5 \mathrm{ml}$ spot urine samples were collected from the participants, and the samples were stored at $4{ }^{\circ} \mathrm{C}$ in transit. The urinary samples were processed and their urinary iodine concentrations (UIC) were measured by acid digestion method (WS/T1072006) [12], and the salt samples were measured by colorimetric titration method (GB/T13025.7-2012) [13] in the laboratory of Fujian Centre for Disease Control and 
Prevention (CDC). Low, medium and high concentration of reference materials were used in the assay which was provided by China National Iodine Deficiency Disorders Reference Laboratory.

\section{Assessments}

Since Fujian's regulated concentration of iodized salt in is $25 \mathrm{mg} / \mathrm{kg}$ after the adjustment, the iodine concentration of qualified table salt should fall in the range of 18$33 \mathrm{mg} / \mathrm{kg}$ while the national standard before 2012 was $35 \mathrm{mg} / \mathrm{kg}$ with the range of $20-50 \mathrm{mg} / \mathrm{kg}$. To assess iodine status in populations, World Health Organization (WHO) recommends median UIC (mUIC) as an index. There are 4 iodine statuses for school-age children and adults: insufficient $(\mathrm{mUIC}<100 \mu \mathrm{g} / \mathrm{L})$, adequate $(100 \mu \mathrm{g} / \mathrm{L} \leq \mathrm{mUIC} \leq$ $199 \mu \mathrm{g} / \mathrm{L})$, above requirements $(200 \leq \mathrm{mUIC} \leq 299 \mu \mathrm{g} / \mathrm{L})$, and excessive $(\mathrm{mUIC} \geq 300 \mu \mathrm{g} / \mathrm{L})$. For pregnant women, they have other 4 cut-off points: insufficient (mUIC < $150 \mu \mathrm{g} / \mathrm{L})$, adequate $(150 \mu \mathrm{g} / \mathrm{L} \leq \mathrm{mUIC} \leq 249 \mu \mathrm{g} / \mathrm{L})$, above requirements $(\mathrm{mUIC} \leq 250 \mu \mathrm{g} / \mathrm{L} \leq 499 \mu \mathrm{g} / \mathrm{L}$ ), and excessive $(\mathrm{mUIC} \geq 500 \mu \mathrm{g} / \mathrm{L})$. For lactating women, $\mathrm{mUIC}<100 \mu \mathrm{g} / \mathrm{L}$ was defined as insufficient, and $\mathrm{mUIC} \geq 100 \mu \mathrm{g} / \mathrm{L}$ was defined as adequate [14].

\section{Quality control}

All the investigators received unified training before the investigation, and they should clearly understand the items of the questionnaire and fill in the questionnaires carefully. Missing items should be avoided. Clean polyethylene containers with caps were used. The correlation coefficient of the standard curve of urine iodine concentration was required to be above 0.999. Standard substances were used before, during and after the tests.

\section{Statistical analysis}

All the data was entered into the database by EPI DATA 3.5.1 software, and the analysis was conducted by SPSS software (SPSS 20.0; IBM Corp, Armonk, NY, USA). The sample size of each area was determined by the variation of UIC; in 2009 the variation of mUIC was set to $20 \%$, the sample size should be greater than 31 ; in 2017 the variation of mUIC was set to $10 \%$, the sample size should be greater than 122 [15]. Since UIC was abnormally distributed, Wilcoxon test was conducted to compare the UIC in each population and area before and after the adjustment, and the UIC was reported as median $(M)$ and interquartile range $\left(\mathrm{IQR}, \mathrm{Q}_{1} \sim \mathrm{Q}_{3}\right.$ ), adults ages were reported as mean \pm standard deviation (SD). All the tests were two-sided and $P<0.05$ was considered statistically significant.

The authors are accountable for all aspects of the work in ensuring that questions related to the accuracy or integrity of any part of the work are appropriately investigated and resolved.

\section{Results}

Sample size by population and geographical locations

Four thousand eight hundred six people participated in the study in 2017 while 2,471 people participated in the study in 2009 (Table 1).

\section{Demographic characteristics of school-age children and adults}

Nine hundred twenty-seven school-age children and four hundred forty-five adults participated in this study in 2009 while 1,113 school-age children and 1,869 adults participated in this study (Table 2).

\section{lodine concentration in salt before and after the adjustment}

The median iodine concentration of table salt was $29.8 \mathrm{mg} / \mathrm{kg}(\mathrm{IQR}=27.0-31.9 \mathrm{mg} / \mathrm{kg}$ ) in 2009 and $23.9 \mathrm{mg} /$ $\mathrm{kg}(\mathrm{IQR}=22.6-25.0 \mathrm{mg} / \mathrm{kg})$ in 2017 (Fig. 1).

\section{Median urinary iodine concentration distribution after the adjustment}

In 2017, for overall school-age children, significantly lower mUICs were observed in the coastal urban area $(P<0.001)$ and non-coastal rural area $(P<0.001)$ compared to 2009 (Fig. 2). mUIC of school-age children in the non-coastal rural area was iodine above requirement $(218.2 \mu \mathrm{g} / \mathrm{L}, \mathrm{IQR}$ [interquartile range] $=148.1-306.5 \mu \mathrm{g} / \mathrm{L})$; pregnant women in non-coastal urban area, coastal rural area and non-coastal area were iodine deficiency $(141.5 \mu \mathrm{g} / \mathrm{L} \quad[\mathrm{IQR}=97.7-207.6 \mu \mathrm{g} / \mathrm{L}], \quad 127.3 \mu \mathrm{g} / \mathrm{L} \quad[\mathrm{IQR}=$ $90.0-184.5 \mu \mathrm{g} / \mathrm{L}]$ and $144.8 \mu \mathrm{g} / \mathrm{L}[\mathrm{IQR}=99.9-184.5 \mu \mathrm{g} / \mathrm{L}]$,

Table 1 Number of samples by population and geographical locations in 2009 and 2017

\begin{tabular}{|c|c|c|c|c|c|c|c|c|}
\hline \multirow[t]{2}{*}{ Location } & \multicolumn{2}{|c|}{ Schoo-age childrenl (n) } & \multicolumn{2}{|c|}{ Adults (n) } & \multicolumn{2}{|c|}{ Pregnant women (n) } & \multicolumn{2}{|c|}{ Lactating women (n) } \\
\hline & 2009 & 2017 & 2009 & 2017 & 2009 & 2017 & 2009 & 2017 \\
\hline Coastal urban area & 155 & 418 & 61 & 255 & 90 & 203 & 93 & 200 \\
\hline Non-coastal urban area & 212 & 505 & 158 & 310 & 110 & 253 & 98 & 250 \\
\hline Coastal rural area & 400 & 631 & 163 & 363 & 242 & 313 & 254 & 301 \\
\hline Non-coastal rural area & 160 & 315 & 63 & 185 & 101 & 150 & 111 & 154 \\
\hline Total & 927 & 1869 & 445 & 1113 & 543 & 919 & 556 & 905 \\
\hline
\end{tabular}


Table 2 Demographic characteristics of school-age children and adults in the year of 2009 and 2017

\begin{tabular}{|c|c|c|}
\hline & 2009 & 2017 \\
\hline \multicolumn{3}{|l|}{ School-age children } \\
\hline \multicolumn{3}{|l|}{ Sex } \\
\hline Male, n (\%) & $469(50.6)$ & $962(51.5)$ \\
\hline Female, n (\%) & $458(49.4)$ & $907(48.5)$ \\
\hline \multicolumn{3}{|l|}{ Age (years) } \\
\hline $8, \mathrm{n}(\%)$ & $225(24.3)$ & $611(32.7)$ \\
\hline $9, \mathrm{n}(\%)$ & $378(40.8)$ & 739 (39.5) \\
\hline $10, \mathrm{n}(\%)$ & $324(35.0)$ & $519(27.8)$ \\
\hline \multicolumn{3}{|l|}{ Adults } \\
\hline \multicolumn{3}{|l|}{ Sex } \\
\hline Male, n (\%) & $220(49.4)$ & $561(50.4)$ \\
\hline Female, n (\%) & $225(50.6)$ & $552(49.6)$ \\
\hline Age (years), mean $\pm S D$ & $33.6 \pm 7.6$ & $35.4 \pm 8.5$ \\
\hline
\end{tabular}

respectively). Moreover, the rest of the subjects in each subgroup were iodine sufficient in 2017. The mUIC of school-age children in the non-coastal rural area $(218.2$ $\mu \mathrm{g} / \mathrm{L} \quad[\mathrm{IQR}=148.1-306.5 \mu \mathrm{g} / \mathrm{L}])$ was still acceptable although it exceeded the cut-off point of $200 \mu \mathrm{g} / \mathrm{L}$.

For adults, the overall iodine status was significantly lower in $2017(166.1 \mu \mathrm{g} / \mathrm{L}$ [IQR = 104.9-243.8 $\mu \mathrm{g} / \mathrm{L}])$ compared to $2009(199.9 \mu \mathrm{g} / \mathrm{L}[\mathrm{IQR}=129.0-304.6 \mu \mathrm{g} / \mathrm{L}])(P<$ 0.001) (Fig. 3).

For overall pregnant women, there is no significant difference between two years $(P=0.21)$, and the mUICs of pregnant women in non-coastal urban area, coastal and non-coastal rural areas were iodine deficiency after adjustment $(141.5 \mu \mathrm{g} / \mathrm{L}[\mathrm{IQR}=97.7-207.6 \mu \mathrm{g} / \mathrm{L}], 127.3 \mu \mathrm{g} /$ $\mathrm{L}[\mathrm{IQR}=90.0-184.5 \mu \mathrm{g} / \mathrm{L}]$ and $144.8 \mu \mathrm{g} / \mathrm{L} \quad[\mathrm{IQR}=99.9-$ $184.5 \mu \mathrm{g} / \mathrm{L}])$ (Fig. 4).

For lactating women, the overall iodine status was significantly lower in $2017(113.8 \mu \mathrm{g} / \mathrm{L}[\mathrm{IQR}=69.6-171.1 \mu \mathrm{g} /$
L]) after the adjustment $(P<0.001)$, and the iodine status was adequate across all area groups (Fig. 5).

\section{Discussion}

The results from this study showed that the coverage of qualified iodized salt in 2017 remained above $90 \%$, and the median iodine concentration significantly decreased from $29.8 \mathrm{mg} / \mathrm{kg}$ in 2009 to $23.9 \mathrm{mg} / \mathrm{kg}$ in 2017 . The results also revealed that the mUICs among school-age children and adults were $100-200 \mu \mathrm{g} / \mathrm{L}$ in 2017 , indicating that the iodine status was adequate with the exception for the above requirements of non-coastal rural school-age children. Although mUICs of non-coastal rural school-age children was still above requirements, iodine concentration experienced a dramatic decrease and finally it was close to the upper boundary of adequacy, suggesting that we reached the expected aim of iodized salt adjustment. However, there was no significant decrease in overall UIC for pregnant women after the adjustment, and only the coastal urban area met the criterion set by WHO among the 4 geographical areas. And mUICs for lactating women remained at an adequate level albeit there was a significant decrease after the adjustment.

The reduced concentration was based on the iodine status among the local people in each province. A total of 13 provinces like Fujian, Zhejiang and Guangxi reduced their concentration of iodized salt from $35 \mathrm{mg} / \mathrm{kg}$ to $25 \mathrm{mg} / \mathrm{kg}$. Similarly, the mUIC of school-age children in Zhejiang Province fell to $174.3 \mu \mathrm{g} / \mathrm{L}$ [16]; Guangxi Province which reduced its iodine concentration to $25 \mathrm{mg} / \mathrm{kg}$ had the similar tendency as well [11]. Yet 11 provinces like Shanghai set their standard of $30 \mathrm{mg} / \mathrm{kg}$ [17]. In addition, some provinces set a combined standard - higher iodine concentration for pregnant women and lower iodine concentration for the other population groups [6].

In this investigation, over $90 \%$ coverage of qualified iodized salt after adjustment indicated that our province

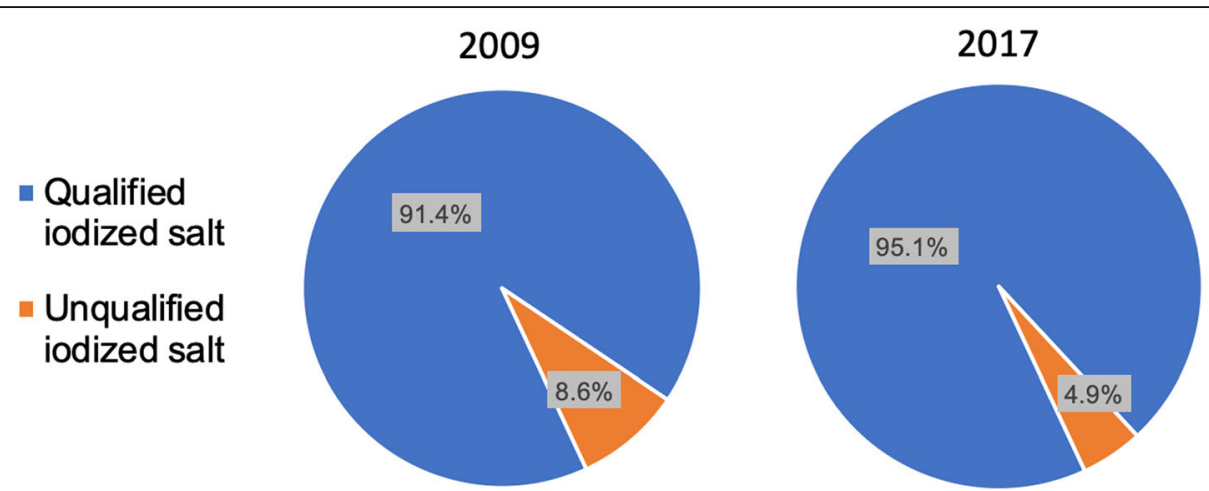

Fig. 1 Percentage of qualified and unqualified iodized salt collected from household in 2009 and 2017. The left pie chart is the percentage of qualified and unqualified iodized salt in 2009 ( $n=522)$, the right pie chart is the percentage of qualified and unqualified iodized salt in 2017 ( $n=566)$ 


\section{School-age Children}

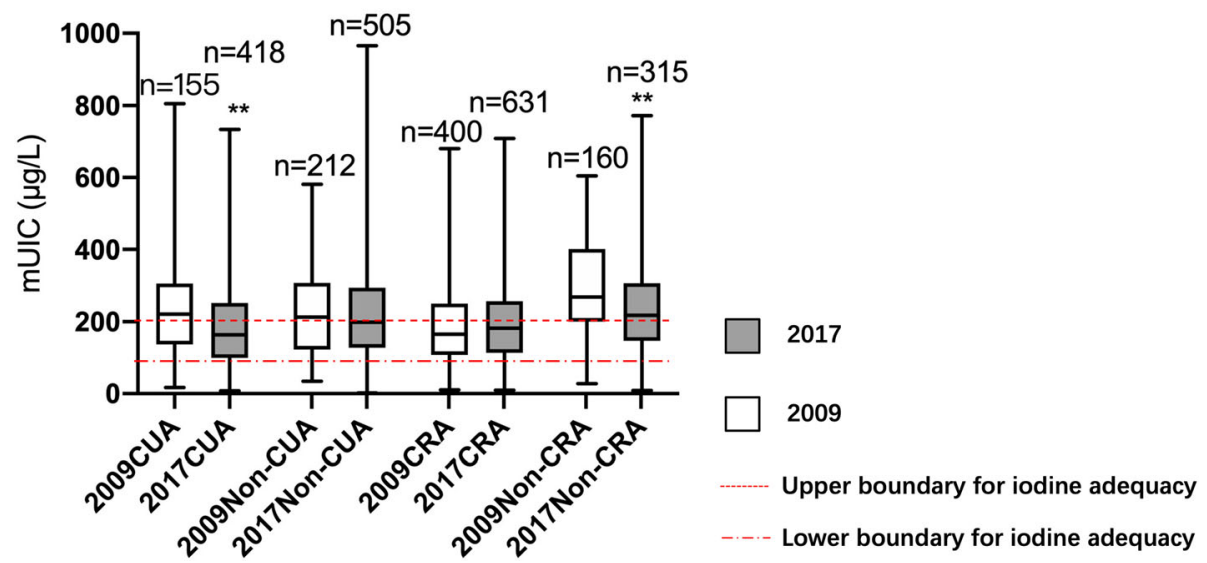

Fig. 2 Comparison of urinary iodine concentration by geographical locations in 2009 and 2017 among school-age children. mUIC: urinary iodine concentration; CUA: coastal urban area; Non-CUA: non-Coastal urban area; CRA: coastal rural area; Non-CRA: non-coastal rural area. ${ }^{* *}$ Urinary iodine concentration (UIC) in 2017 was significantly lower compared to 2009 in each area $(P<0.05)$ by Wilcoxon test $(P<0.001)$

still satisfied the requirement of eliminating IDD, and the difference before and after the adjustment was statistically significant suggesting that this reduction was in place. Nonetheless, the median iodine concentration of table salt was below the theoretical value, especially in the year of 2009. We supposed that the factories lowered the iodine concentration with the purpose of cost reduction as long as it was still within the interval. Certainly, they could not avoid the loss of iodine in production which seemed to be another reason. We also noticed that the mUICs in 2017 were much higher in school-age children $(186.5 \mu \mathrm{g} / \mathrm{L})$ and adults $(165.8 \mu \mathrm{g} / \mathrm{L})$ compared to pregnant women $(141.4 \mu \mathrm{g} / \mathrm{L})$. The reasons for deficiency among pregnant are: (1) thyroid hormone production increases by $50 \%$ during gestation [18]; (2) iodine is given priority to fetus in order to satisfy the fetus's nervous system development [19]; (3) the iodine renal clearance during pregnancy increases [19-21]; (4) $\mathrm{T}_{3}$ deiodinase activity increases [19]. In addition, vomit during pregnancy could partly cause iodine loss. Also, some pregnant women chose a low-salt diet in the prevention of edema and pregnancy-induced hypertension. Another finding was that in 2017 almost all the mUICs was higher of each population in non-coastal area than

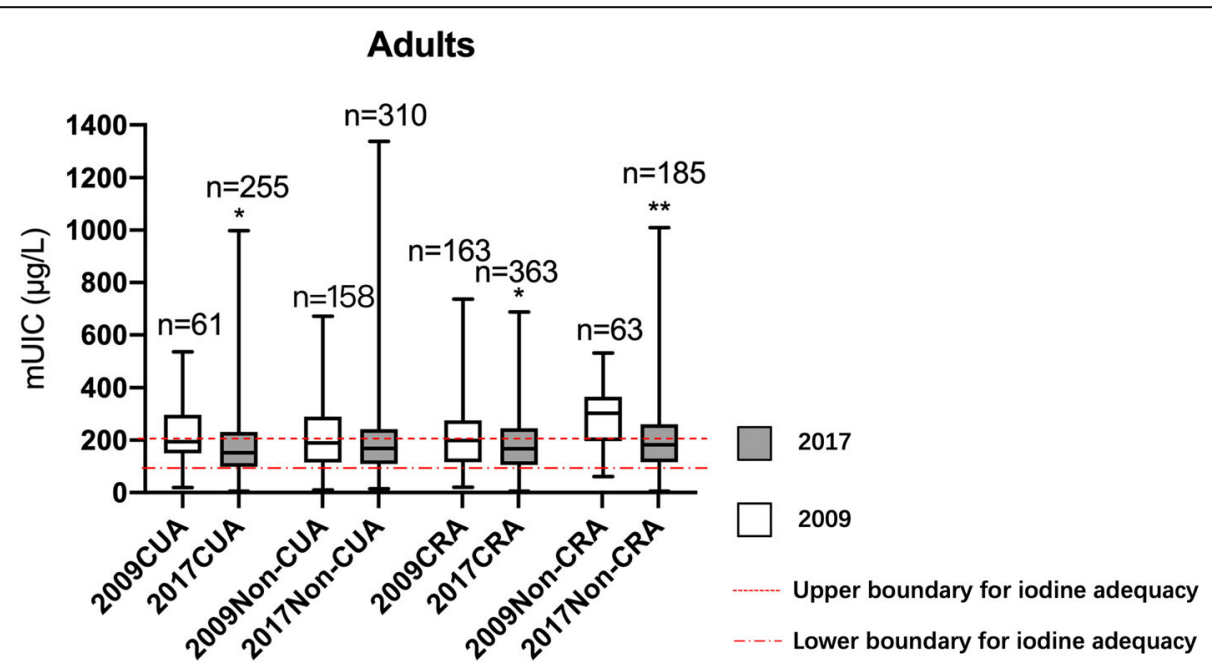

Fig. 3 Comparison of urinary iodine concentration by geographical locations in 2009 and 2017 among adults. mUIC: median urinary iodine concentration; CUA: coastal urban area; Non-CUA: non-coastal urban area; CRA: coastal rural area; Non-CRA: non-coastal rural area. Urinary iodine concentration (UIC) in 2017 was significantly lower compared to 2009 in each area $(P<0.05)$ by Wilcoxon test. ${ }^{* *}$ Urinary iodine concentration (UIC) in 2017 was significantly lower compared to 2009 in each area $(P<0.05)$ by Wilcoxon test $(P<0.001)$ 


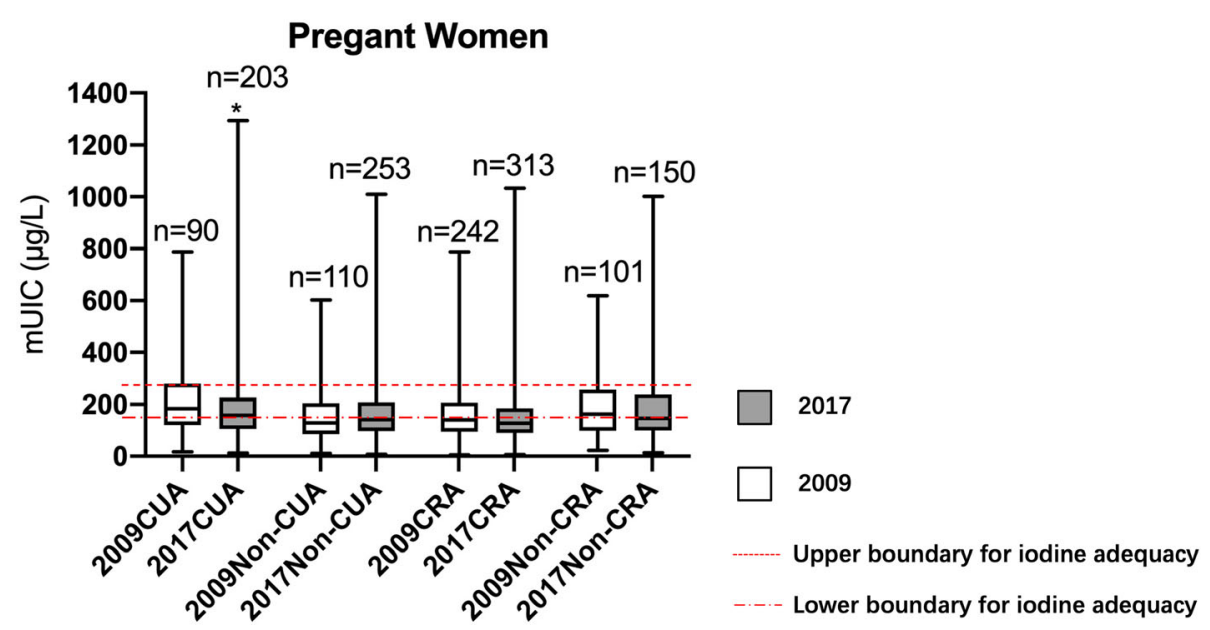

Fig. 4 Comparison of urinary iodine concentration by geographical locations in 2009 and 2017 among pregnant women. mUIC: median urinary iodine concentration; CUA: coastal urban area; Non-CUA: non-coastal urban area; CRA: coastal rural area; Non-CRA: non-coastal rural area. ${ }^{*}$ Urinary iodine concentration (UIC) in 2017 was significantly lower compared to 2009 in each area $(P<0.05)$ by Wilcoxon test

coastal area wherever they were rural or urban, and we suppose it may be associated with the salty diet among non-coastal residents.

The results suggest that the adjustment was suitable for school-age children, adults and lactating women. The mUICs in 2017 among school-age children, adults and lactating women significantly declined but still maintained at the adequate level after the adjustment of iodine concentration. The results showed that the mUIC among lactating women was still above the cut-off point of iodine adequate based on criterion by $\mathrm{WHO} /$ United Nations International Children's Emergency Fund (UNICEF) [11], but there was a substantial decline especially for the rural women, the median urinary iodine was only $105.8 \mu \mathrm{g} / \mathrm{L}$ for coastal area and $110.2 \mu \mathrm{g} / \mathrm{L}$ for non-coastal area, which closed to the cut-off point. Given that iodine for the new-borns is mainly from lactating women and lactating women are of a high risk of iodine deficiency, the United States The Pediatrics Society recommends that lactating women should take iodine supplements at least $150 \mu \mathrm{g}$ per day [22]. Thus, it is essential to monitor and assess their iodine status or even adopt some strategies target at lactating women.

However, there was no significant difference in mUIC among pregnant women - the mUIC was below $150 \mu \mathrm{g} / \mathrm{L}$ both before and after the adjustment, defined as iodine

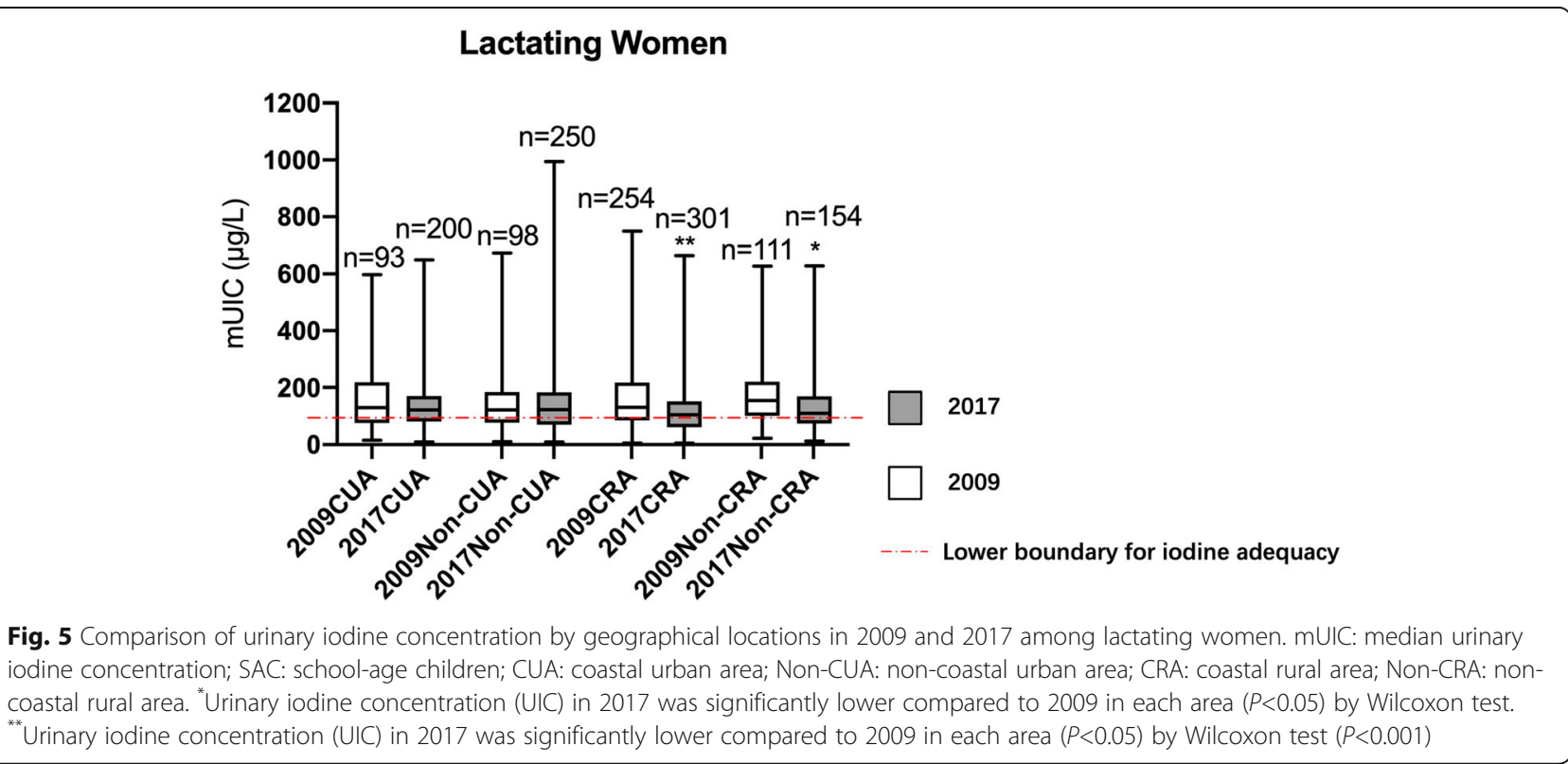


deficient according to criterion recommended by $\mathrm{WHO} /$ UNICEF [11]. Hence, we can say that the adjustment had its limited impact on pregnant women. Similarly to Fujian and other province, the pregnant women in some developed countries face iodine deficiency as well, such as Austria, Norway and Sweden [23, 24]. Studies have shown that iodine deficiency during pregnancy can cause adverse effects on the nervous system [25-28] and psychiatric development of the offspring [25, 29]. The earlier the iodine supplementation of pregnant women, the better the mental development of the offspring [30]. As it is difficult for pregnant women to satisfy the iodine requirements by iodized salt only, we suggest iodine supplement tablets $(150 \mu \mathrm{g} /$ day $)$ as most European countries [31] and the enriched iodized food intake, such as laver and kelp.

The primary strength of the study is the large sample size - we recruited 2,471 participants in 2009 and 4,806 participants in 2017. A limitation of this study is that UICs could be influenced by water consumption which can differ per season as people tend to drink more in summer and less in winter, and the current study collected the samples between December to April. Secondly, iodine status was assessed by spot urine sample which could be greatly affected by laver and kelp, followed by shellfish while other seafood does not contain so much iodine; if some participants ate these seafood on the day of sampling, as a consequence, their urine would be detected with high iodine concentration, so spot urine sample cannot fully represent the actual daily iodine consumption.

\section{Conclusions}

Our findings suggest that the iodine status, in general, is adequate among school-age children, adults and lactating women after the adjustment of universal salt iodization program in Fujian Province, indicating the current iodized salt concentration is more appropriate for the populations and we reached the aim of iodized salt adjustment. However, pregnant women were iodine insufficient after adjustment so additional measures should be taken. Iodized salt, as the major approach of iodine supplement in our country, should be continuously promoted in our province even in coastal area and islands.

\section{Abbreviations \\ IDD: lodine deficiency disorders; mUIC: Median urine iodine concentration; UIC: Urine iodine concentration; CDC: Centre for Disease Control; WHO: World Health Organization; IQR: Interquartile range; UNICEF: United Nations International Children's Emergency Fund}

\section{Acknowledgements}

The authors are grateful to all the participating children and their guardians, adults, pregnant women and lactating women. The authors also thank the staff of county and district CDCs who managed urine sample collection.

\section{Authors' contributions}

Zhihui Chen designed the study. Yixuan Lin and Diqun Chen collected and analysed the data; Zhihui Chen and Jiani Wu took part in the field investigation and completed the laboratory analysis. Yixuan Lin prepared for the first manuscript. All the authors approved the final manuscript. Yixuan Lin and Diqun Chen contributed equally to this article.

\section{Funding}

Construction of Fujian Provincial Scientific and Technological Innovation Platform (2019Y2001). The funders had no role in the design, analysis or writing of this article.

\section{Availability of data and materials \\ The datasets used during the current study are available from the corresponding author on reasonable request.}

\section{Ethics approval and consent to participate}

This study was conducted in accordance with the Declaration of Helsinki. Ethics approval was obtained from the Ethics Committee of Fujian Provincial CDC (No. 2017002). Written informed consent was obtained from every participant or the guardian of the children before their urine samples were collected.

\section{Consent for publication}

Not applicable.

\section{Competing interest}

None of the authors has conflict of interest to declare.

\section{Author details}

${ }^{1}$ Fujian Center for Disease Control and Prevention, Department of Endemic Diseases, Fujian, No. 76 Jintai Road, Fujian 350001 Fuzhou, People's Republic of China. ${ }^{2}$ Department of Global Public Health, Karolinska Institutet Tomtebodavägen 18, 17165 Solna, Sweden. ${ }^{3}$ School of Public Health, Fujian Medical University, University of New Area, No.1 Xueyuan Road, Fujian 350108 Fuzhou, People's Republic of China.

Received: 14 September 2020 Accepted: 17 February 2021

Published online: 23 February 2021

\section{References}

1. Mcnulty BA, Nugent AP, Walton J, et al. lodine intakes and status in Irish adults : is there cause for concern ? Brit J Nutr. 2017:117(3):422-31.

2. Bath SC, Walter A, Taylor A, et al. lodine deficiency in pregnant women living in the South East of the UK : the influence of diet and nutritional supplements on iodine status. Brit J Nutr. 2014;111(9):1622-31.

3. Kasaniam $\mathrm{GH}$, Hasennajad $M$. The effects of excess iodine on immune system; an in-vitro study. KAUMS J. 2013;10(7):609-10. 16.

4. Katagiri $R$, Yuan $X$, Kobayashi $S$, et al. Effect of excess iodine intake on thyroid diseases in different populations: A systematic review and metaanalyses including observational studies. PLoS One. 2017;10(3):e0173722.

5. Budak N, Bayram F, Günay O, et al. lodine deficiency: An important and severe public health problem in Kayseri, Central Anatolia. J Endocrinol Invest. 2007;1(11):920-4.

6. Codling $\mathrm{K}$, Chen Z, Hongmei $\mathrm{S}$, et al. China : leading the way in sustained IDD elimination: the international council for control of iodine deficiency disorders (ICCIDD) global network. IDD Newsl. 2014;42(2):1-5.

7. Wassie MM, Abebe Z, Tariku A, et al. lodine status five years after the mandatory salt iodization legislation indicates above requirement: a cross sectional study in Northwest Ethiopia. BMC Nutr. 2018;1(1):52.

8. Andersson M, Berg G, Eggertsen $\mathrm{R}$, et al. Adequate iodine nutrition in Sweden : a cross-sectional national study of urinary iodine concentration in school-age children. Eur J Clin Nutr. 2009;63(7):828-34.

9. Huynh D, Condo D, Gibson R, et al. lodine status of postpartum women and their infants in Australia after the introduction of mandatory iodine fortification. Brit J Nutr. 2017;117(12):1656-62.

10. United Nations International Children's Emergency Fund. The State of the World's Children 2012: Children in an Urban World. eSocialSciences; 2012.

11. Sun D, Codling K, Chang S, et al. Eliminating lodine Deficiency in China: Achievements, Challenges and Global Implications. Nutrients. 2017;9(4):361. 
12. Chinese Criteria Publishing. Method for Determination of lodine in Urine by $\mathrm{As}^{3+}-\mathrm{Ce}^{4+}$ Catalytic Spectrophotometry, WS/T 107-2006. Beijing: China's Ministry of Health (in Chinese).

13. Chinese Criteria Publishing. General Test Method in Salt Industry Determination of lodic lon, GB/T 13025.7-2012. Beijing: China's Ministry of Health (in Chinese).

14. WHO. World Health Organization. Assessment of iodine deficiency disorders and monitoring their elimination: a guide for programme managers. 3rd ed. Geneva: WHO (WHO/UNICEF/ICCIDD); 2007.

15. Andersen S, Karmisholt J, Pedersen KM, et al. Reliability of studies of iodine intake and recommendations for number of samples in groups and in individuals. Br J Nutr. 2008;99(4):813-8.

16. Zou Y, Lou X, Ding G, et al. lodine nutritional status after the implementation of the new iodized salt concentration standard in China. BMC Public Health. 2014;14(1):1-5.

17. Wang Z, Liu P, Su X, Zou S, Song J, Liu S. A Comparison of lodine Status in Children and Pregnant Women After a Policy Change in the lodized Salt Standard in Shanghai, China. Biol Trace Elem Res. 2018;1 (2):275-81. 185(.

18. Alexander EK, Pearce EN, Brent GA, Brown RS, Chen H, Dosiou C, Grobman WA, Laurberg P, Lazarus JH, Mandel SJ, Peeters RP. 2017 Guidelines of the American Thyroid Association for the diagnosis and management of thyroid disease during pregnancy and the postpartum. Thyroid. 2017:27(3):315 - 89.

19. Alemu A, Terefe B, Abebe M, Biadgo B. Thyroid hormone dysfunction during pregnancy: A review. Int J Reprodu BioMed. 2016;14(11):677.

20. Wu H, Wang H. Observation of iodine nutrition in focus population after down-regulation of iodised salt standard in Hainan. Chin Trop Med. 2015;15: 57-66. (in Chinese).

21. Ding $R$, Wang B, Yang $Y$, et al. Study on iodine nutritional status and its influencing factors among pregnant women in rural and urban areas of Hefei City. ï» ¿Chin J Dis Control Prev. 2014;18:151-4. (in Chinese).

22. Rogan WJ, Paulson JA, Baum C, et al. Council on environmental health. Policy statement: lodine deficiency, pollutant chemicals, and the thyroid: new Information on an old problem. Pediatrics. 2014;133(6):1163-6.

23. Lindorfer $H$, Krebs $M$, Sager $M$, et al. lodine deficiency in pregnant women in Austria. Eur J Clin Nutr. 2015;69(3):349-54.

24. Brantsæter AL, Erlund I, Laurberg P, et al. lodine status in the Nordic countries - past and present. Food Nutr Res. 2016;1(1):31969. 60.

25. Bath SC, Steer CD, Golding J, et al. Effect of inadequate iodine status in UK pregnant women on cognitive outcomes in their children: results from the Avon Longitudinal Study of Parents and Children (ALSPAC). Lancet. 2013; 27(9889):331-7. 3826.

26. Velasco I, Bath SC, Rayman MP. lodine as essential nutrient during the first 1000 days of life. Nutrients. 2018;10(3):290.

27. Moog NK, Entringer S, Heim C, Wadhwa PD, Kathmann N, Buss C. Influence of maternal thyroid hormones during gestation on fetal brain development. Neuroscience. 2017;342:68-100

28. UNICEF. Guidance on the Monitoring of Salt lodization Programmes and Determination of Population lodine Status. New York: UNICEF; 2018.

29. Zimmermann MB. lodine deficiency in pregnancy and the effects of maternal iodine supplementation on the offspring: a review. Am J Clin Nutr. 2009;89(2):668S-72S

30. Berbel P, Mestre JL, Santamaria A, et al. Delayed neurobehavioral development in children born to pregnant women with mild hypothyroxinemia during the first month of gestation: the importance of early iodine supplementation. Thyroid. 2009;1(5):511-9.

31. Zimmermann M, Delange F. lodine supplementation of pregnant women in Europe: a review and recommendations. Eur J Clin Nutr. 2004:58(7):979-84.

\section{Publisher's Note}

Springer Nature remains neutral with regard to jurisdictional claims in published maps and institutional affiliations.

\section{Ready to submit your research? Choose BMC and benefit from:}

- fast, convenient online submission

- thorough peer review by experienced researchers in your field

- rapid publication on acceptance

- support for research data, including large and complex data types

- gold Open Access which fosters wider collaboration and increased citations

- maximum visibility for your research: over $100 \mathrm{M}$ website views per year

At BMC, research is always in progress.

Learn more biomedcentral.com/submissions 